TP Periodica Polytechnica Chemical Engineering

https://doi.org/10.3311/PPch.10044

Creative Commons Attribution (i)

RESEARCH ARTICLE

\section{Removal of Acetone from Wastewater by POSS Loaded PDMS Membrane}

\author{
Filiz Ugur Nigiz ${ }^{1 *}$, Nilufer Durmaz Hilmioglu ${ }^{1}$
}

Received 20 September 2016; accepted after revision 06 December 2016

\begin{abstract}
The waste-water of the chemical processes includes hundreds of hazardous pollutants with low concentration. Although the emission of trace amounts of these chemicals is allowed by the laws, they are quite harmful to the water ecosystem and the human health. These chemicals including the acetone, toluene, phenol, and esters are defined as volatile organic compounds (VOCs). Separation of the VOCs from the large volume of industrial waste-water is required practically complicated and advanced processes. In this approach, more economically and efficient separation methods can be more favorable such as pervaporation. Pervaporation $(P V)$ is an attractive and promising method for separation the small amount of dissolved chemicals from the waste-water. Pervaporative separation does not need any toxic solvent or external heat energy during the separation process. Therefore, it is defined as a cost effective and environmentally friendly process.

In this study, acetone was selected as a VOC component and it was selectively separated from the model mixture (acetone-water) by pervaporation where the poly(hedral oligomeric silsesquioxane)(POSS) loaded poly(dimethyl siloxane) hydrophobic membrane was used. The structure of the membrane was characterized by scanning electron and polarized microscopy methods. The surface structure of the membrane was also analyzed by contact angle measurements. Effects of feed temperature and acetone-water concentration on separation performance were evaluated in terms of the total flux and acetone separation factor. Compared to the pristine PDMS membrane, 212\% improvement on separation factor was achieved by 10 wt.\% POSS incorporated membrane. The highest acetone separation factor was obtained as 237 when the temperature was $30^{\circ} \mathrm{C}$ and the acetone concentration was $1 \%$.
\end{abstract}

\section{Keywords}

acetone removal, pervaporation, poly(dimethyl siloxane), poly(hedral oligomeric silsesquioxane)

\footnotetext{
${ }^{1}$ Department of Chemical Engineering, Faculty of Engineering, Kocaeli University, Kocaeli, 41380, Turkey

*Corresponding author, e-mail: filiz.ugur@kocaeli.edu.tr
}

\section{Introduction}

Volatile organic compounds (VOCs) are petrochemical based hazardous compounds that are present in almost all chemical waste or product stream at different range of their composition. Discharging of VOC included waste-water to the domestic water is a potential threat for the human health and water ecosystem. Therefore, it is mandatory to remove those chemicals from the waste-stream below the level of ppm $[1,2]$. Because of the low concentration of VOCs in water, advanced and costly methods are required to purify water [3]. The most common techniques used for VOCs removals are adsorption, air stripping, oxidation, distillation, and biological treatment methods are used to remove the VOCs from product or wastestream [4]. In the case of the adsorption method; zeolites, clays or different adsorbents are used to retain these impurities. However, a regeneration step is required to recover adsorbent to use over again. Air stripping is a relatively cost-effective process and it does not need additional chemicals to remove VOCs. However, it is only feasible if the VOCs are present at high concentration in waste-water. Contrary to the air stripping, biological treatment is only effective if the concentration of VOC is low [5]. Membrane based separation process such as pervaporation (PV) is an alternative technique to purify the waste-water efficiently [6-8].

Pervaporation is defined as a permeation selective evaporation and it is suitable to separate close boiling point, thermally-sensitive, and azeotropic mixtures selectively [9, 10]. It is clean and cost effective method to separate the small amounts of organics from the water. Based on the non-porous selective membrane usage, pervaporative separation character is clearly explained by solution-diffusion phenomena [11-13]. This model basically consists of three main steps for a liquid mixture separation; sorption of the selected component on the surface of the membrane, diffusion throughout the membrane, desorption to the downstream side of the membrane in vapour phase. Compared the other membrane process, pervaporative separation is operated without a remarkable energy requirement. Currently, there are several commercial PV units for dehydration of bio-ethanol and $\operatorname{VOC}$ removal $[14,15]$. 
Still, academic studies centre upon the pervaporative desulfurization, aroma recovery, chemical synthesis, waste treatment, and desalination processes [16-18].

The pervaporative VOCs separation is an attractive research area. However, it is needed to make much effort on membrane preparation with high separation performance. Based on their low concentration of VOCs pollutants in the waste-water, it is required to separate them selectively from the bulk water stream. Until now, there are many of reported studies related to pervaporative separation of alcohol, ether, toluene, phenol, and benzene [19-21].

In the literature, acetone removal by pervaporation has also been studied [22-24]. In those studies, plain polymeric membranes have been used. Experiments are still being made to provide suitable conditions and desired separation performance with different membranes. Acetone is very important chemical intermediates due to its wide variety of the industrial application from plastic and drugs. It is also produced by acetone-butanol-ethanol fermentation and it must be removed from the fermentation broth to preserve the bio-activity of the microorganism [23]. The solubility of the acetone in water is very high even at low temperature. Thereby, it becomes hard to separate the dissolved acetone from the water by the conventional separation technique [25]. In the literature, purification of dilute acetone-water mixture by PV has been studied by the hydrophobic membrane [26, 28].

Hydrophobic membranes are preferred to separate organic chemicals from water or to separate the organic mixtures from the each other. These types of membranes such as poly(dimethylsiloxane)(PDMS) exhibit a strong affinity to the organic solvents. However, the virgin hydrophobic membranes exhibit very low flux or low organic selectivity. Therefore, it is needed to improve both productivity and selectivity of the polymer by making some modifications (e.g. cross-linking, blending, inorganic or organic incorporation).

POSS (poly(hedral oligomeric silsesquioxane) is a cagelike nano-sized particle that includes various types of organic groups such as alkyl, olefin, alcohol, acid, amine, epoxy and sulfonate [29]. Recently, due to the good compatibility property of the POSS within the polymers, it has been preferred as active filler in the mixed matrix membranes. Moreover, it gives a good thermal, mechanical and chemical stability to the polymeric matrix [30]. POSS is also used as filler in gas separation, catalytic reaction, and pervaporation [29]. The octavinyl POSS is a hydrophobic materials and it is very effective to separate organics from the water selectively.

The main objective of the present study is preparation of the POSS loaded PDMS hybrid membrane with good separation performance. Due to the hydrophobic nature of the POSS, the effect of POSS incorporation on the separation performance has been investigated in the present study. To the best our knowledge, POSS incorporated PDMS membranes have not been used for acetone removal earlier. The structural properties of the PDMS and octavinyl POSS are very similar. Fig. 1 shows the schematic representation of the vinyl terminated PDMS, octavinyl POSS and benzoyl peroxide. In this respect, good structural compatibility will be expected in membrane formation. Therefore, the hybrid membrane is estimated to show a good selective separation capability.
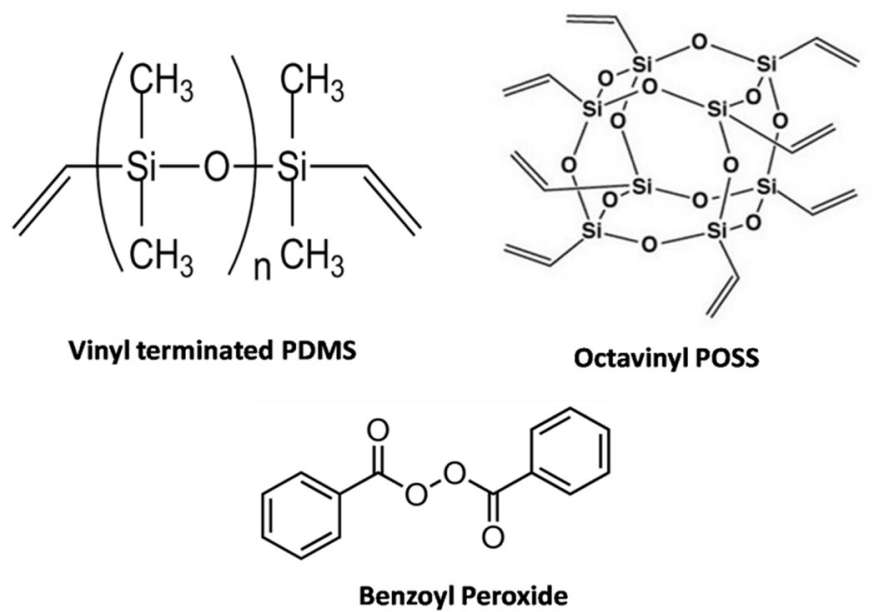

Fig. 1 Schematic representation of the chemicals

\section{Experimental \\ 2.1 Materials}

Vinyl terminated PDMS (Silastic New GP30) was kindly supplied by Dow Chemical Company. Octavinyl POSS was purchased from Hybrid Plastics. Benzoyl peroxide (BPO) (98\% purity) as cross-linking agent and acetone (99.5\% purity) were purchased from Aldrich Chemicals.

\subsection{System description}

The pervaporation test system is shown in Fig. 2. The system consists of a membrane cell, a vacuum pump and three cold traps. The membrane cell is present in an oven to operate the experiment at a constant temperature. The temperature of the membrane cell is controlled by a thermometer. A mechanical stirrer is also put on the membrane cell to provide a constant agitation. The effective separation area of the membrane is $19.625 \mathrm{~cm}^{2}$, and the volume capacity of the cell is $250 \mathrm{ml}$.

Experiments were carried out at different temperatures, with a constant pressure difference. The upstream side of the cell was kept at atmospheric pressure and 1 mbar pressure was applied at the downstream side to create a concentration gradient between the sides of the membrane. The vacuum contributed to evaporate the permeate solution at the operating temperature. Vapour stream was condensed at the cold traps by liquid nitrogen. Liquid permeate samples were taken from the traps with one hourly interval to determine the concentrations. 


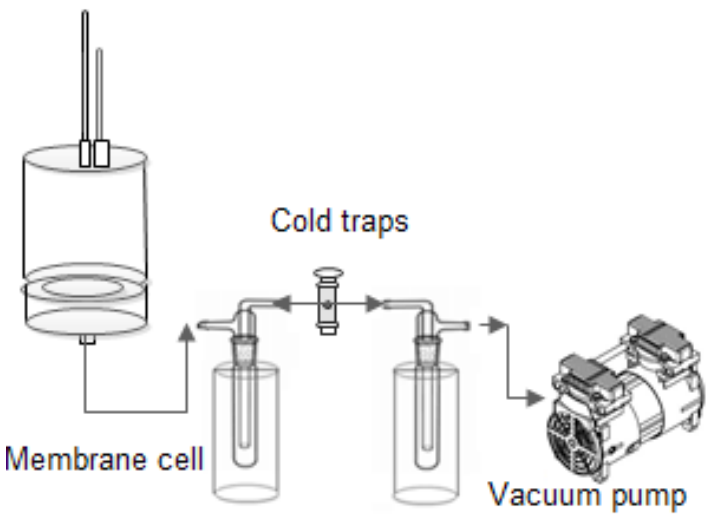

Fig. 2 Experimental pervaporation set-up

\subsection{Membrane preparation}

POSS loaded PDMS membrane was prepared by the phase inversion method. In this study, POSS was added as selective filler to increase the acetone separation factor. For this purpose, $10 \mathrm{wt} . \%$ PDMS was dissolved in chloroform and the solution was stirred for 10 hours at $50{ }^{\circ} \mathrm{C}$. After a homogeneous solution had been obtained, different amount of POSS and $4 \mathrm{wt} . \%$ dehumidified benzoyl peroxide (respect to the total polymer weight) were added to the polymer solution and stirred for 2 hours at the room temperature. The solution was poured on to a Teflon plate and dried over-night. Then, the polymeric film was cured in a vacuum oven at $185^{\circ} \mathrm{C}$ for 6 hours to complete the cross-linking reaction between the peroxide and vinyl groups of the PDMS and POSS. This process was important to remove the residue solvent and benzoic acid from the membrane.

\subsection{Membrane characterization}

The structure of the hybrid POSS-PDMS membrane was analyzed by a JEOL JSM-6335 F Field Emission Scanning Electron microscope. Liquid nitrogen was used to cryogenically break the membranes. The samples were coated with gold before the analysis. POSS distribution was also analyzed by Nikon Polarized Light Microscope. Hydrophobicity of the membrane was tested with contact angle measurement by means of KVK Attension Instrument.

\subsection{Pervaporative separation}

The pervaporative separation of the acetone-water mixture was studied at different temperatures over a range from $30^{\circ} \mathrm{C}$ to $60{ }^{\circ} \mathrm{C}$ and different acetone concentrations $(1,3,5$ and 10 wt.\% acetone). Separation performance of the study was evaluated in terms of the total flux and acetone separation factor.

\subsection{Analysis}

The concentration of the permeate solution was determined by Agilent 7980 gas chromatography (GC) with Thermal Conductive Detector (TCD). HP-FFAP polyethylene glycol capillary column was settled in GC. The detector temperature was $280^{\circ} \mathrm{C}$ and the oven temperature was $220^{\circ} \mathrm{C}$.

\subsection{Sorption test}

Sorption experiments were applied to determine the affinity of the membrane to the immersed component. Membranes were cut into equal pieces having $1 \mathrm{~cm}^{2}$ area and they were immersed in acetone-water solutions (3 wt.\%, 10 wt. $\%$ and 100 wt. $\%$ acetone). The time-dependent sorption capacity and degree of swelling values of the membranes were obtained by this experiment. The degree of swelling (DS) was calculated by the Eq. (1)

$$
D S=\left(\mathrm{W}_{\mathrm{i}}-\mathrm{W}_{\mathrm{f}}\right) * 100 /\left(\mathrm{W}_{\mathrm{i}}\right)
$$

where the $\mathrm{W}_{\mathrm{i}}$ and $\mathrm{W}_{\mathrm{f}}$ represent the initial and final weight of membrane samples respectively.

Sorption experiments were also applied to the non-crosslinked pure PDMS membrane in order to determine the effect of cross-linking reaction on separation performance of the membrane.

\subsection{Calculation}

The separation performance of the membrane was evaluated by calculation of the total flux $(J)\left(\mathrm{kg} / \mathrm{m}^{2} . \mathrm{h}\right)$ and acetone separation factor $(\beta)$. Flux was calculated by means of the measured mass of the permeate solution by the Eq. (2).

$$
J=M_{\mathrm{p}} / A \cdot t
$$

The acetone concentration in the permeate stream was obtained from the GC analysis. The acetone separation factor was calculated by the Eq. (3).

$$
\beta=\left(P_{\text {Act }} / P_{\mathrm{w}}\right) /\left(F_{\text {Act }} / F_{\mathrm{w}}\right)
$$

$M_{p}(\mathrm{~kg})$ represents the total mass of the permeate, $A\left(\mathrm{~m}^{2}\right)$ is the effective separation area of the membrane, $t(\mathrm{~h})$ is operating time. $P_{\text {Act }}$ and $P_{w}$ describe the mass fractions of acetone and water in the permeate stream respectively. $F_{A c t}$ and $F_{w}$ represent the mass fractions of acetone and water in the feed mixture respectively.

\section{Results and Discussion \\ 3.1 Membrane characterization}

Membrane characterizations were applied to determine the morphological and structural behavior of the pristine and POSS loaded membrane. SEM micrographs of the POSS loaded PDMS membranes are seen in Fig. 3. Fig. 3a represents the homogeneous distribution of the POSS particles on the surface of the PDMS matrix. Fig. 3b confirms that the POSS is fully compatible with the PDMS. There is no contact-free region between the boundary layers of two different materials. Fig. $3 \mathrm{c}$ shows that POSS particles aggregate on the top surface of the membrane. This can be attributed to the slow evaporation process of the membrane preparation procedure. Fig. $3 \mathrm{~d}$ confirms the non-defected membrane formation and good adhesion between the PDMS and POSS particles. 

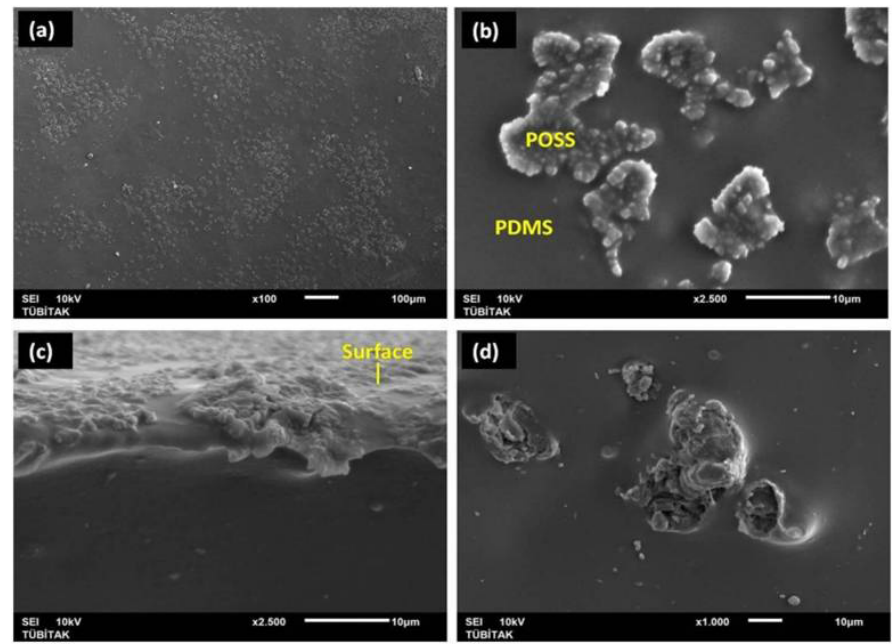

Fig. 3 Surface (a and b) and cross-sectional (c and d) SEM micrographs of POSS loaded PDMS membrane

Polarized electron microscopy images are shown in Fig. 4. While the light phase represents the POSS particles, the dark region is corresponding to the PDMS matrix. The images indicate the homogeneous POSS distribution on the surface of the PDMS.

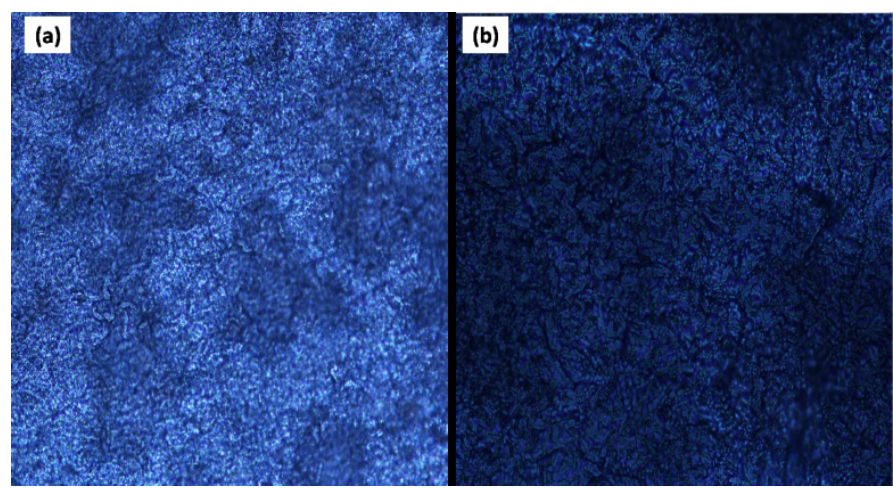

Fig. 4 POSS distribution onto membrane under polarized light

Hydrophilic-hydrophobic characters of the pristine and hybrid membranes were analyzed by means of the contact angle measurement under pure water drop. There are many of characterization techniques to determine the hydrophobicity of a material. Among these, the contact angle measurement is the simplest one. When the water droplets contact with a pure surface, an angle occurs. In the case of the hydrophobic materials, this angle is mostly near or greater than $90^{\circ}$. If the hydrophobicity increases on the surface, the angle also increases. Fig. 5a and Fig. 5b show the contact angle measurement results of the pristine and POSS loaded membrane respectively. As it can be evaluated, both the pristine and the hybrid membranes were hydrophobic. When the POSS materials are incorporated in the PDMS matrix, the contact angle and hydrophobicity of the membrane enhanced. In the literature, it has been reported that the maximum water contact angle on a smooth surface is $120^{\circ}$. After that point, polymer is defined as super-hydrophobic [28]. As it is represented in Fig. $4 \mathrm{~b}$ that the POSS loaded membrane shows a super-hydrophobic surface. Meanwhile, it is expected that the hybrid membrane may show better acetone separation factor than that of the pristine PDMS membrane.
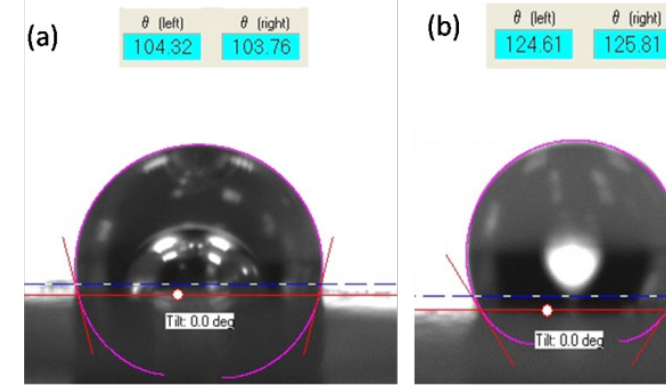

Fig. 5 Contact angle results of pristine (a) and POSS loaded (b) membrane

\subsection{Sorption results}

According to the solution-diffusion model, the prior factor for determining the separation efficiency is the membrane-solvent affinity. This factor also plays an important role to select an appropriate membrane material. Theoretically, solubility parameters are used to predict the relationship between the membrane material and solvent. Experimentally, sorption experiments contribute to select a suitable material for the membrane to be used in PV.

In this study, the acetone and water were used in pervaporation experiments. Hence, the affinities of the pristine and POSS loaded membranes to acetone-water solutions were studied by means of sorption experiments. Fig. 6 indicates the degree of swelling results of the pristine and hybrid membranes for different concentrations of acetone-water mixtures. PDMS showed a strong affinity to the acetone. Therefore, the swelling degree enhanced when the acetone concentrations were increased. Remarkably, swelling degree of the hybrid membrane was lower compared to the pristine PDMS. POSS addition might lead to a decrement in plasticization effect of the PDMS and the swelling degree was restricted as expected. In this case, it is possible to predict that acetone may be selectively separated from the model solution by the hybrid PDMS membrane.

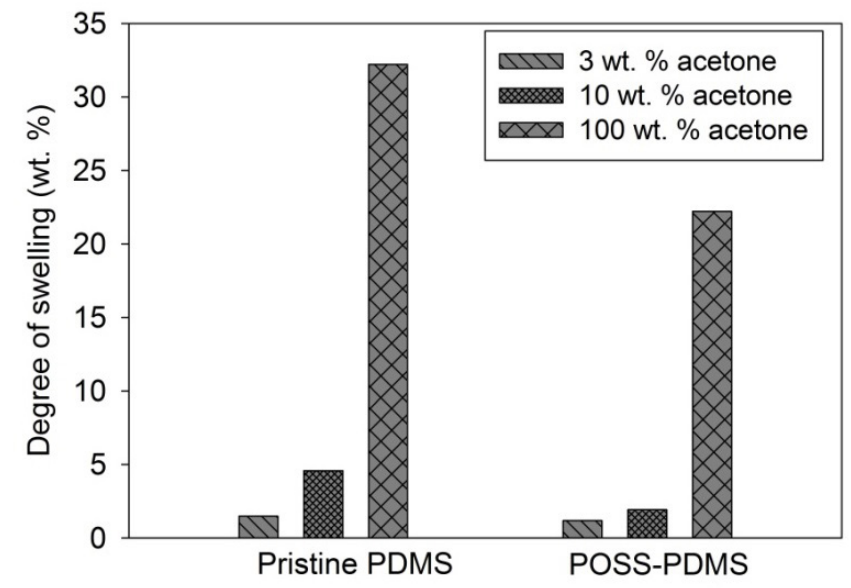

Fig. 6 Degree of swelling results (Pristine PDMS and 10 wt.\% POSS incorporated PDMS) 


\subsection{Effect of POSS loading on separation performance}

Fig. 7 shows the separation results of the hybrid membrane in terms of the total flux and acetone separation factor. As it can be seen from the Fig. 7, flux value decreased from $0.141\left(\mathrm{~kg} / \mathrm{m}^{2} . \mathrm{h}\right)$ to $0.124\left(\mathrm{~kg} / \mathrm{m}^{2} . \mathrm{h}\right)$ slightly when the POSS loading was increased from 0 wt.\% to 15 wt.\%. Indeed, this result was predictable from the data of the swelling experiments. As it was mentioned before, swelling degree of the membrane was restricted and the plasticizing effect was reduced by the POSS incorporation. PDMS has flexible chain structure. Compared to PDMS, the solvent transition is difficult throughout the intermolecular void-spaces of the POSS particles. Additionally, these types of fillers may cause a decrement in permeability of solvent by leading an increment in tortuous pathway. Because of the drastic difference between the flux results of the pristine and hybrid membrane, the separation result of this study is an example of that claiming.

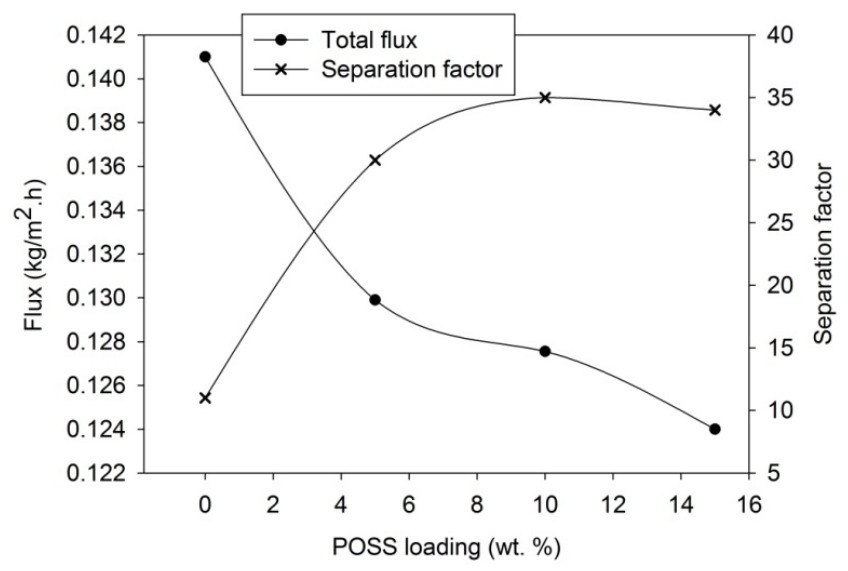

Fig. 7 Effect of POSS edition on flux and separation factor $\left(50{ }^{\circ} \mathrm{C}, 5\right.$ wt. $\%$ acetone $)$

Unlike the flux, acetone separation factor showed a rising trend with filler incorporation up to a certain point. This result was attributed to the restricted chain mobility and swelling degree of the polymer by addition of the POSS. After $10 \mathrm{wt} . \%$ POSS loading ratio, a little decreasing was seen in separation factor caused by excessive POSS loading. Because of the agglomeration and non-homogenized distribution of the particles in the matrix, selective separation capability of the composite membrane could be negatively affected [31]. Hence, optimum POSS ratio was determined as $10 \mathrm{wt} . \%$. Effect of operating condition on separation performance was evaluated at constant POSS loading (10 wt.\%). When the separation factor was evaluated, 200\% improvement was achieved by POSS addition.

\subsection{Effect of acetone concentration on separation performance}

The relationship between acetone and PDMS was mentioned in the Section 3.2. Hence, the flux increment with the increasing acetone concentration was an expected result. This claiming was confirmed as it can be observed at Fig. 8. When acetone concentration increased from $1 \mathrm{wt} . \%$ to $10 \mathrm{wt} . \%$, flux increased from $0.008 \mathrm{~kg} / \mathrm{m}^{2} . \mathrm{h}$ to $0.1 \mathrm{~kg} / \mathrm{m}^{2} \mathrm{~h}$. As the acetone concentrations were increased in the feed mixture, the degree of swelling enhanced due to the hydrophobic nature of the PDMS. Flux enhancement might be explained by the easy permeation ability of the solvents through the swollen molecular void spaces of the PDMS membrane. However, water passage was also allowed by the swollen chains of the membrane. Hence, separation factor decreased as it is seen in Fig. 8.

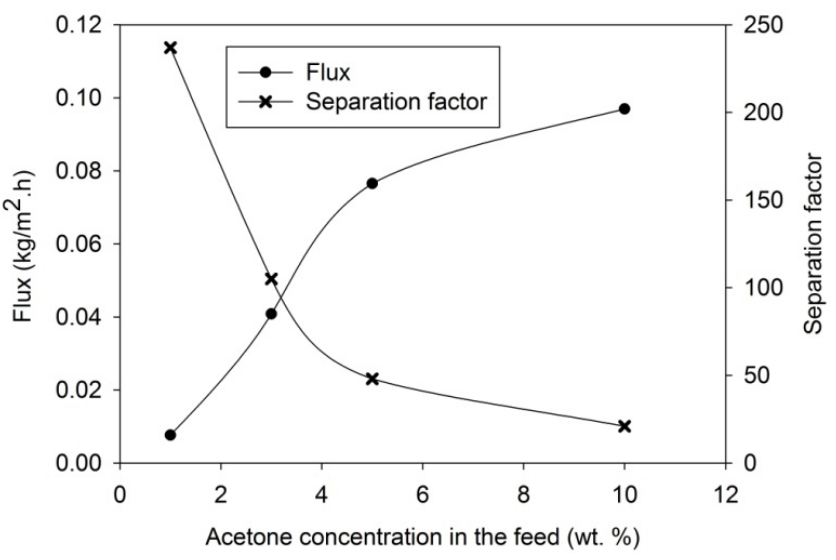

Fig. 8 Flux and separation factor results at different feed concentrations $\left(30{ }^{\circ} \mathrm{C}, 10\right.$ wt. $\%$ POSS $)$

Hydrophobic membranes are suitable to separate small amount of organic compounds from the water. If the water purification is the subject, obtaining a high separation factor associated with an applicable flux is desired. These pollutants are present as dissolved form in the water with a very low concentration. Hence, it is expected to observe very low permeate flux for the pervaporative organic-water removal. As it is shown in Fig. 8, the best separation factor was achieved as 237 when the acetone concentration in water was $1 \mathrm{wt} \%$. When the acetone concentration increased from $1 \mathrm{wt} \%$ to $10 \mathrm{wt} . \%$, separation factor decreased from 237 to 21.

\subsection{Effect of temperature on separation performance}

Fig. 9 indicates the effect of temperature on the separation performance. When the temperature increased from $30{ }^{\circ} \mathrm{C}$ to $60{ }^{\circ} \mathrm{C}$, flux enhanced from $0.04 \mathrm{~kg} / \mathrm{m}^{2} . \mathrm{h}$ to $0.092 \mathrm{~kg} / \mathrm{m}^{2} . \mathrm{h}$. Temperature directly affects the structural properties of the polymer and the thermodynamic behavior of the solvents. Pervaporation is a membrane separation process where a non-porous selective membrane is used. Meanwhile, the compound diffusion occurs throughout the molecular void's spaces of the membrane material. In the case of a polymeric membrane, temperature accelerates the segmental motion of the flexible polymer. This circumstance leads to an enlargement in the void-spaces of the polymer. Especially for the rubbery polymer that has low glassy transition temperature $(\mathrm{Tg})$, permeability 
enhances with the increasing temperature. Besides the structural properties of the membrane, the diffusivity and solubility of the components increase with temperature. The flux increment is also related to the physicochemical properties of the components. Due to the high solubility parameter of the acetone into water, water drifts along with the acetone molecules and the separation factor decreases. The trend of the pilots in Fig. 9 is an example of this case. As it is indicated, the flux and the separation factor showed a trade-off trend depending on the temperature.

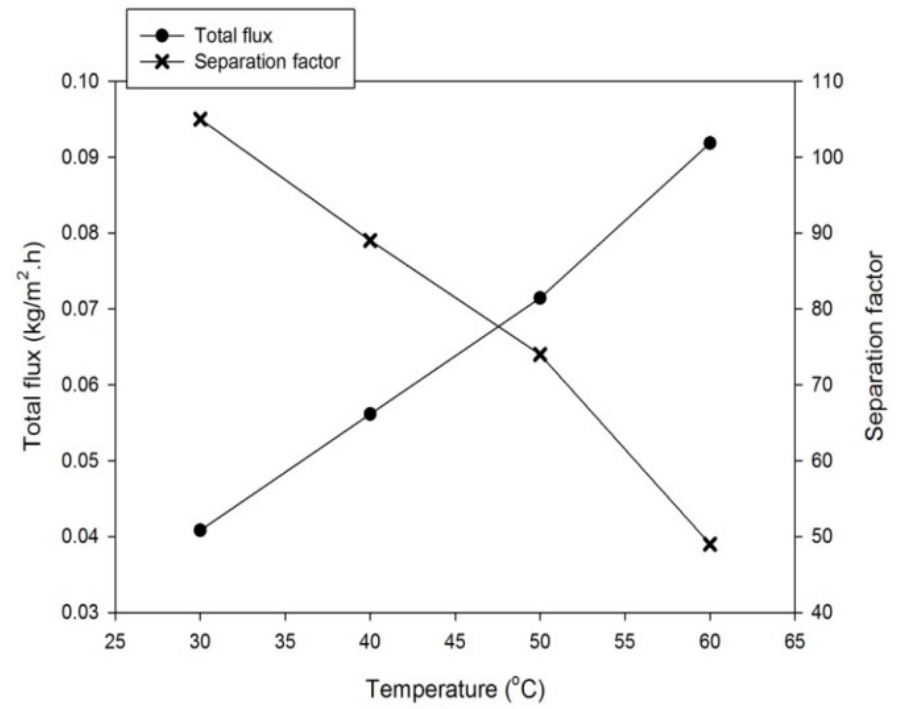

Fig. 9 Effect of temperature on flux and separation factor (10 wt.\% POSS, 3 wt. \% acetone)

Although the flux enhanced, the selective property of membrane was suffered from the enlarged void-spaces of the polymer. The acetone separation factor decreased from 105 to 48 as the temperature increased from $30^{\circ} \mathrm{C}$ to $60{ }^{\circ} \mathrm{C}$ as expected.

\subsection{Comparison of results with literature data}

There are two important outputs for all membranes to be used in pervaporation. Separation factor defines the selective character. Flux determines the productivity of the membrane and it should be a reasonable value. Flux and separation factor can show a trade-off trend with temperature or feed concentration. In order to compare the performance of the system under the different conditions, pervaporation separation index has been defined (PSI). It allows for the evaluation of the overall pervaporation performance. It can be defined as the product of total permeation flux and selectivity. However, this definition changes according to the viewpoint of authors. Some authors claimed that the separation factor cannot be 1 . This mean, there is no selective separation. If there is no selective separation, then it is not true to mention the "pervaporation separation index". Thereby PSI is defined as Eq. (4).

$$
P S I=J *(\beta e t-1)
$$

The comparison of the pervaporative separation of acetone results from the literature and the present study are given in Table 1.

Table 1 Comparison of results with literature data

\begin{tabular}{llllll}
\hline $\begin{array}{l}\text { Membrane } \\
\text { type }\end{array}$ & $\begin{array}{l}\text { Acetone (wt.\%) } \\
(\text { Temperature })\end{array}$ & $\begin{array}{l}\text { Flux } \\
\left(\mathrm{g} \cdot \mathrm{m}^{-2} \mathrm{~h}^{-1}\right)\end{array}$ & $\beta$ & $\begin{array}{l}\text { PSI } \\
\left(\mathrm{g} \cdot \mathrm{m}^{-2} \mathrm{~h}^{-1}\right)\end{array}$ & Ref. \\
\hline B-ZSM-5 & $5\left(30^{\circ} \mathrm{C}\right)$ & 180 & 33 & 5760 & 32 \\
Pervap 4060 & $4\left(30^{\circ} \mathrm{C}\right)$ & 0.25 & 72 & 1800 & 27 \\
PDMS & $1\left(30^{\circ} \mathrm{C}\right)$ & 9 & 4.2 & 28.8 & 23 \\
$\begin{array}{l}\text { POSS- } \\
\text { PDMS }\end{array}$ & $3\left(30^{\circ} \mathrm{C}\right)$ & 40 & 105 & 4160 & $\begin{array}{l}\text { Present } \\
\text { study }\end{array}$ \\
\hline
\end{tabular}

To the best our knowledge, this is the first study that incorporates the POSS material into a PDMS for purification of acetone-water mixtures. As can it be understood from the table, very good separation factor associated with a reasonable flux value was achieved in the present study. And the PSI factor confirmed that result.

\section{Conclusions}

In the present study, the pervaporative separation of acetone-water mixtures was studied by means of the pristine PDMS and POSS loaded PDMS membranes. Optimum POSS loading was determined as $10 \mathrm{wt} . \%$ and compared to pristine ones, $212 \%$ separation factor improvement was achieved. The highest separation factor was obtained as 237 (1 wt.\% acetone) at $30{ }^{\circ} \mathrm{C}$. Better PSI that means high separation factor with acceptable flux was achieved at $50{ }^{\circ} \mathrm{C}$. As a result of this study, it is concluded that the POSS incorporated PDMS membrane could be a suitable membrane to separate organics from water and it would be a good commercial membrane candidate after some improvements.

\section{Acknowledgments}

This study was financially supported by Scientific Research Projects Unit of Kocaeli University (Grant Number : 2016/040)

\section{Abbreviations}

POSS Poly(hedraloligomeric silsesquioxane)

PV Pervaporation

BPO Benzoyl peroxide

PEBA Poly(ether block amide)

PDMS Poly(dimethylsiloxane)

PMS Poly(methyl siloxane)

PTFE Polytetrafluoroethylene

PVDF Poly(vinylidene fluoride)

SEM Scanning electron microscope

VOC Volatile organic compound 


\section{Symbols}

\section{A}

F

J

P

PSI

$\mathrm{t}$

Wp

$\beta$

Act

W

\section{References}

[1] Berenjian, A., Chan, N., Malmiri, H. J. "Volatile Organic Compounds Removal Methods: A Review." American Journal of Biochemistry and Biotechnology. 8, pp. 220-229. 2012.

https://doi.org/10.3844/ajbbsp.2012.220.229

[2] Khan, F. I., Ghoshal, A. K. "Removal of Volatile Organic Compounds from polluted air." Journal of Loss Prevention in the Process Industries. 13, pp. 527-545. 2000. https://doi.org/10.1016/S0950-4230(00)00007-3

[3] Peng, M., Vane, L. M., Liu, S. X. "Recent advances in VOCs removal from water by pervaporation." Journal of Hazardous Materials. B98, pp. 69-90. 2003.

https://doi.org/10.1016/S0304-3894(02)00360-6

[4] Kim, H. J., Nah, S. S., Min, B. R. "A new technique for preparation of PDMS pervaporation membrane for VOC removal." Advances in Environmental Research. 6, pp. 255-264. 2002.

https://doi.org/10.1016/S1093-0191(01)00056-9

[5] Kujawa, J., Cerneaux, S., Kujawski, W. "Removal of hazardous volatile organic compounds from water by vacuum pervaporation with hydrophobic ceramic membranes." Journal of Membrane Science. 474, pp. 11-19. 2015. https://doi.org/10.1016/j.memsci.2014.08.054

[6] Garcia, V., Pongracz, E., Phillips, P. S., Keiski, R. L. "From waste treatment to resource efficiency in the chemical industry: recovery of organic solvents from waters containing electrolytes by pervaporation." Journal of Cleaner Production. 39, pp. 146-153. 2013.

https://doi.org/10.1016/j.jclepro.2012.08.020

[7] Uragam, T., Fukuyama, E., Miyata, T. "Selective removal of dilute benzene from water by poly(methyl methacrylate)-graft-poly(dimethylsiloxane) membranes containing hydrophobic ionic liquid by pervaporation." Journal of Membrane Science. 510, pp. 131-140. 2016.

https://doi.org/10.1016/j.memsci.2016.01.057

[8] Ramaiah, K. P., Satyasri, D., Sridhar, S., Krishnaiah, A. "Removal of hazardous chlorinated VOCs from aqueous solutions using novel ZSM-5 loaded PDMS/PVDF composite membrane consisting of three hydrophobic layers." Journal of Hazardous Materials. 261, pp. 362-371. 2013. https://doi.org/10.1016/j.jhazmat.2013.07.048

[9] Nunes, S.P., Peinemann, K.V. "Membrane Technology in the Chemical Industry." 2nd ed., Wiley, Germany. 2006. https://doi.org/10.1002/3527600388

[10] Bowen, T. C., Noble, R. D., Falconer, J. L. "Fundamentals and applications of pervaporation through zeolite membranes." Journal of Membrane Science. 245, pp. 1-33. 2004.

https://doi.org/10.1016/j.memsci.2004.06.059

[11] Wijmans, J. G., Baker, R. W. "The Solution Diffusion Model." Journal of Membrane Science. 107, pp. 1-21. 1995.

https://doi.org/10.1016/0376-7388(95)00102-I
[12] Schaetzel, P., Vauclair, C., Nguyen, Q. T., Bouzerar, R. "A simplified solution-diffusion theory in pervaporation: the total solvent volume fraction model." Journal of Membrane Science. 244, pp. 117-127. 2004. https://doi.org/10.1016/j.memsci.2004.06.060

[13] Valentínyi, N., Mizsey, P. "Comparison of pervaporation models with simulation of hybrid separation processes." Periodica Polytechnica Chemical Engineering. 58(1), pp. 7-14. 2014. https://doi.org/10.3311/PPch.7120

[14] Qiao, X. "The Development Of Pervaporation Membranes For Alcohol Dehydration." Ph.D. Dissertation, National University of Singapore. Singapore. 2007.

[15] Garcia, V., Pongracz, E., Phillips, P. S., Keiski, R. "From waste treatment to resource efficiency in the chemical industry: recovery of organic solvents from waters containing electrolytes by pervaporation." Journal of Cleaner Production. 39, pp. 146-153. 2013. https://doi.org/10.1016/j.jclepro.2012.08.020

[16] Leppäjärvi, T., Malinen, I., Korelskiy, D., Kangas, J., Hedlund, J., Tanskanen, J. "Pervaporation of Ethanol/Water Mixtures Through a High-Silica MFI Membrane: Comparison of Different Semi-Empirical Mass Transfer Models." Periodica Polytechnica Chemical Engineering. 59(2), pp. 111-123. 2015. https://doi.org/10.3311/PPch.7665

[17] Debarati, M. "Desulfurization of Gasoline by Pervaporation." Separation \& Purification Reviews. 41, pp. 97-125. 2012. https://doi.org/10.1080/15422119.2011.573044

[18] Hornyák, L., Hornyák-Holczman, A. N., Márki, E., Vatai, G. "Recovery of aroma compounds from model solution by pervaporation membrane." Periodica Polytechnica Chemical Engineering. 58(1), pp. 15-19. 2014. https://doi.org/10.3311/PPch.7123

[19] Uragami, T., Matsuoka, Y., Miyata, T. "Removal of Dilute Benzene in Water through Ionic Liquid/Poly(Vinyl Chloride) Membranes by Pervaporation." Journal of Membrane Science \& Research. 5, pp. 20-25. 2016.

[20] Mohammadi, S., Kargari, A., Sanaeepur, H., Abbassian, K., Najafi, A., Mofarrah, E. "Phenol removal from industrial wastewaters: a short review." Desalination and Water Treatment. 53, pp. 2215-2234. 2015. https://doi.org/10.1080/19443994.2014.883327

[21] Patil, M. B., Aminabhavi, T. M. "Pervaporation separation of toluene/alcohol mixtures using silicalite zeolite embedded chitosan mixed matrix membranes." Separation and Purification Technology. 62, pp. 128-136. 2008. https://doi.org/10.1016/j.seppur.2008.01.013

[22] Marki, E., Lenti, B., Vatai, G., Bekassy-Molnar, E. "Clean technology for acetone absorption and recovery." Separation and Purification Technology. 22, pp. 377-382. 2001.

https://doi.org/10.1016/S1383-5866(00)00121-0

[23] Izak, P., Ruth, W., Fei, Z., Dyson, P. J., Kragl, U. "Selective removal of acetone and butan-1-ol from water with supported ionic liquidpolydimethylsiloxane membrane by pervaporation." Chemical Engineering Journal. 139, pp. 318-321. 2008. https://doi.org/10.1016/j.cej.2007.08.001

[24] Koch, K., Gorak, A. "Pervaporation of binary and ternary mixtures of acetone, isopropyl alcohol and water using polymeric membranes: Experimental characterisation and modeling." Chemical Engineering Science. 115, pp. 95-114. 2014.

https://doi.org/10.1016/j.ces.2014.02.009

[25] Hernandez, R., Zappi, M., Colucci, J., Jones, R. "Comparing the performance of various advanced oxidation processes for treatment of acetone contaminated water." Journal of Hazardous Materials. 92, pp. 33-50. 2002. https://doi.org/10.1016/S0304-3894(01)00371-5

[26] Zhang, Q. Z., Li, B. B., Li, P. X., Li, D. Y., Yang, P., Sun, D. "Pervaporation of acetone/water mixture by PDMS-PTFE/PVDF composite membrane." Desalination and Water Treatment. 57, pp. 23489-23504. 2016. https://doi.org/10.1080/19443994.2015.1137785 
[27] Khayet, M., Cojocaru, C., Zakrzewsk, T. G. "Studies on pervaporation separation of acetone, acetonitrile and ethanol from aqueous solutions." Separation and Purification Technology. 63(2), pp. 303-310. 2008. https://doi.org/10.1016/j.seppur.2008.05.016

[28] Arkles, B. "Hydrophobicity,Hydrophilicity and Silanes." Paint \& Coatings Industry magazine. 20, pp. 114-119. 2006.

[29] Le, N. L., Wang, Y., Chung, T. S. "Pebax/POSS mixed matrix membranes for ethanol recovery from aqueous solutions via pervaporation." Journal of Membrane Science. 379, pp. 174-183. 2011. https://doi.org/10.1016/j.memsci.2011.05.060

[30] Konietzny, R., Koschine, T., Rätzke, K., Staudt, C. "POSS-hybrid membranes for the removal of sulfur aromatics by pervaporation." Separation and Purification Technology. 123, pp. 175-182. 2014.

https://doi.org/10.1016/j.seppur.2013.12.024
[31] Nigiz, F. U., Ozkoc, G., Hilmioglu, N. D. "A study on the separation performance of zeolite filled thin film composite poly(dimethyl siloxane) membrane." Materials and Design. 88, pp. 942-949. 2015. https://doi.org/10.1016/j.matdes.2015.09.055

[32] Gholabroodi, B. E., Babaluo, A. A. "Pervaporation of acetone/water mixtures through nanostructure B-ZSM-5 zeolite membrane." In: Proceedings of the 4th International Conference on Nanostructures. pp. 12101212. 2010. 